The following is the accepted manuscript of the original article:

Marcel Melzer, Thomas Waechtler, Steve Müller, Holger Fiedler, Sascha Hermann, Raul D. Rodriguez, Alexander Villabona, Andrea Sendzik, Robert Mothes, Stefan E. Schulz, Dietrich R.T. Zahn, Michael Hietschold, Heinrich Lang and Thomas Gessner "Copper oxide atomic layer deposition on thermally pretreated multi-walled carbon nanotubes for interconnect applications", Microelectron. Eng. 107, 223-228 (2013).

Digital Object Identifier: 10.1016/j.mee.2012.10.026

Available via http://www.sciencedirect.com or http://dx.doi.org/10.1016/j.mee.2012.10.026

(C) 2013 Elsevier B.V. 


\title{
Copper oxide atomic layer deposition on thermally pretreated multi-walled carbon nanotubes for interconnect applications
}

\author{
Marcel Melzer ${ }^{a}$, Thomas Waechtler ${ }^{a, b,{ }^{*}}$, Steve Müller ${ }^{b}$, Holger Fiedler ${ }^{b}$, Sascha Hermann ${ }^{a, b}$, \\ Raul D. Rodriguez ${ }^{\mathrm{c}}$, Alexander Villabona ${ }^{\mathrm{c}}$, Andrea Sendzik ${ }^{\mathrm{d}}$, Robert Mothes ${ }^{\mathrm{e}}$, \\ Stefan E. Schulz ${ }^{a, b}$, Dietrich R.T. Zahn ${ }^{c}$, Michael Hietschold ${ }^{d}$, Heinrich Lang ${ }^{e}$, Thomas Gessner ${ }^{a, b}$ \\ ${ }^{a}$ Fraunhofer Institute for Electronic Nano Systems (ENAS), Technologie-Campus 3, D-09126 Chemnitz, Germany \\ ${ }^{b}$ Center for Microtechnologies, Chemnitz University of Technology, Reichenhainer Str. 70, D-09107 Chemnitz, Germany \\ ${ }^{c}$ Semiconductor Physics, Chemnitz University of Technology, Reichenhainer Str. 70, D-09107 Chemnitz, Germany \\ ${ }^{d}$ Solid Surfaces Analysis, Chemnitz University of Technology, Reichenhainer Str. 70, D-09107 Chemnitz, Germany \\ ${ }^{e}$ Inorganic Chemistry, Chemnitz University of Technology, Straße der Nationen 62, D-09107 Chemnitz, Germany \\ * Corresponding author: Tel.: +49 (0)371 45001-280, Fax: +49 (0)371 45001-380, E-Mail: thomas.waechtler@enas.fraunhofer.de
}

\section{Abstract:}

Carbon nanotubes (CNTs) are a highly promising material for future interconnects. It is expected that a decoration of the CNTs with Cu particles or also the filling of the interspaces between the CNTs with Cu can enhance the performance of CNT-based interconnects. The current work is therefore considered with thermal atomic layer deposition (ALD) of $\mathrm{Cu}_{\mathrm{x}} \mathrm{O}$ from the liquid $\mathrm{Cu}(\mathrm{I}) \beta$-diketonate precursor $\left[\left({ }^{n} \mathrm{Bu}{ }_{3} \mathrm{P}\right){ }_{2} \mathrm{Cu}(\mathrm{acac})\right]$ and wet oxygen at $135^{\circ} \mathrm{C}$. This paper focuses on different thermal in-situ pre-treatments of the CNTs with $\mathrm{O}_{2}, \mathrm{H}_{2} \mathrm{O}$ and wet $\mathrm{O}_{2}$ at temperatures up to $300^{\circ} \mathrm{C}$ prior to the ALD process. Analyses by transmission electron microscopy show that in most cases the $\mathrm{Cu}_{\mathrm{x}} \mathrm{O}$ forms particles on the multi-walled CNTs (MWCNTs). This behavior can be explained by the low affinity of $\mathrm{Cu}$ to form carbides. Nevertheless, also the formation of areas with rather layer-like growth was observed in case of an oxidation with wet $\mathrm{O}_{2}$ at $300^{\circ} \mathrm{C}$. This growth mode indicates the partial destruction of the MWCNT surface. However, the damages introduced into the MWCNTs during the pre-treatment are too low to be detected by Raman spectroscopy.

\section{Introduction}

Carbon nanotubes (CNTs) are a highly promising material for future interconnects due to the remarkable properties they combine such as high thermal conductivity [1,2], ballistic transport over distances in the $\mu \mathrm{m}$-range $[3,4]$ and the ability to carry high current densities with low electro migration [5]. To make CNT-based interconnects competitive to the currently used copper technology, several challenges have to be overcome, such as formation of low-resistivity contacts, aligned growth both for vertical and horizontal interconnects with high density [6].

The filling of the spaces between the CNTs with a conductive material is an approach to attenuate the high requirements with respect to the growth density of the CNTs. The electrical resistance of CNT filled vias can be improved at constant CNT density by just enhancing the conductivity of the filling material between the CNTs. Up to now, the CNTs are typically embedded into $\mathrm{SiO}_{2}$ in order to stabilize them for a subsequent planarization of the interconnect structures by chemical mechanical polishing (CMP) [7]. Additional to the stabilization effect of this process, it is expected that an encapsulation of the CNTs in Cu instead of $\mathrm{SiO}_{2}$ would have at least two advantages: First, the space between the CNTs would also contribute to the electrically current transport, because the interspaces would be filled up with the electrical conductive $\mathrm{Cu}$ instead of the insulating $\mathrm{SiO}_{2}$. Secondly, already the decoration of the CNTs with metallic Cu particles could increase the conductivity of the CNTs due to charge transfer from the Cu to the CNTs $[8,9]$.

Due to large aspect ratios which occur in CNT-based vias, an appropriate process for their metallization has to be found. The combination of a conformal Cu seed layer deposited by 
thermal ALD with the subsequent filling of the interspaces by chemical vapor deposition (CVD) or electrochemical deposition (ECD) appears promising for embedding the CNTs into $\mathrm{Cu}$. Since $\mathrm{Cu}$ can be grown by the thermal ALD of copper oxide and subsequent reduction $[10,11]$, the ALD of copper oxide on multi-walled CNTs (MWCNTs) is studied in this work.

Because ALD relies on the interaction of the precursor with reactive surface groups and since perfect CNTs are chemically inert, it is necessary to provide such surface groups on the CNTs prior to the ALD process. A multiplicity of various approaches for such as functionalization of the CNT surface can be found in the literature. An overview is given by Marichy et al. [12]. A common method is the treatment of the CNTs with nitric acid or a mixture of nitric and sulfuric acid at temperatures near the boiling point of the used acid mixture $\left(120-140^{\circ} \mathrm{C}\right)[13,14]$. Nevertheless, by this aggressive oxidation technique a high percentage of the CNTs is destroyed. Additionally, the acids would also attack the metal contacts of the CNTs [15]. Another pretreatment is the formation of a double layer of $\mathrm{NO}_{2}$ and trimethylaluminum (TMA) around the CNTs by the alternating injection of $\mathrm{NO}_{2}$ and TMA into the reaction chamber at ambient temperature [16]. However, since the $\mathrm{NO}_{2}$ is only physisorbed on the CNTs, adhesion problems occur. Due to the disadvantages of many pretreatments, a new approach was tested within this study. Different thermal oxidations of the CNTs with oxygen, water vapor, and wet oxygen in the temperature range from $100^{\circ} \mathrm{C}$ to $300^{\circ}$ at a pressure of 1.33 mbar were carried out and their influence onto a subsequent $\mathrm{Cu}_{x} \mathrm{O}$ ALD process was investigated.

\section{Materials and Methods}

CNT samples: For this study vertically aligned MWCNTs were synthesized by chemical vapor deposition. The process temperature during the CNT growth was approx. $600^{\circ} \mathrm{C}$.

Area-selective growth of the CNTs was enabled by depositing the Ni catalyst either on Ta or on $\mathrm{W}$. Outside the vias the interaction of the $\mathrm{Ni}$ catalyst with the $\mathrm{W}$ layer suppresses the growth of CNTs. On the other hand, inside the vias the Ni/Ta bilayer enables the aligned growth of MWCNTs with a diameter of $(14 \pm 3) \mathrm{nm}$ and 12 to 16 shells, see Fig. 1 . The vias are $2 \mu \mathrm{m}$ wide and $800 \mathrm{~nm}$ deep. The growth of the MWCNTs as well as the patterning of the samples is described more detailed in the work of Hermann [17].

Thermal oxidation and ALD process: The oxidation as well as the ALD processes were carried out in a cold-wall, 4 in. single-wafer reactor. The process chamber is evacuated by a roots pump backed by a rotary pump. During the thermal oxidation as well as the ALD process the pressure inside the reactor is regulated to 1.33 mbar by a butterfly valve between the process chamber and the roots pump. The 4-in. wafers on which the samples were placed were heated resistively by a graphite heater during the processes. Prior to the ALD process, the CNTs were thermally oxidized by oxygen, water vapor or wet oxygen within a temperature range from $100^{\circ} \mathrm{C}$ to $300^{\circ} \mathrm{C}$, see Fig. 2. A maximum oxidation temperature of $300^{\circ} \mathrm{C}$ was chosen to ensure the preservation of the vertical alignment of the CNTs during the pre-treatment [18]. The flow rates of the various used oxidation agents as well as of $\mathrm{Ar}$ can be found in Table I. The oxidation was performed for 30 minutes. After the oxidation, the CNTs were cooled down in-situ to the ALD process temperature of $135^{\circ} \mathrm{C}$. The used $\mathrm{Cu}_{x} \mathrm{O}$ precursor Bis(tri-n-butylphosphane)copper(I)acetylacetonate $\left[\left({ }^{n} \mathrm{Bu}_{3} \mathrm{P}\right)_{2} \mathrm{Cu}(\mathrm{acac})\right]$ was synthesized by published methods [19]. Each ALD cycle consists of 4 steps summarized in Table II. In all cases the ALD process was carried out for 400 cycles. Therefore the occurrence of a growth incubation time of the $\mathrm{Cu}_{\mathrm{x}} \mathrm{O}$ on the CNTs cannot be evaluated within this paper. The growth per cycle (GPC) of the $\mathrm{Cu}_{x} \mathrm{O}$ depends strongly on the substrate as 
shown by Waechtler [20]. The smallest value for the GPC of $0.05 \AA /$ cycle was observed on wet $\mathrm{SiO}_{2}$ substrates. A maximum GPC of 0.13-0.15 $\AA$ /cycle was observed on $\mathrm{Ru}$. These values for the GPC are rather low compared, for example, to $\mathrm{Al}_{2} \mathrm{O}_{3} \mathrm{ALD}$ processes ( $\mathrm{GPC}=$ 1.1-1.2 $\AA$ /cycle ) [21]. Possibly this is due to the bulky ligands of the $\mathrm{Cu}(\mathrm{I}) \beta$-diketonate precursor, which cause steric hindrance. While more details of the ALD process have already been described earlier [20,22], further investigations of the growth behavior on different substrates are in progress.

Sample characterization: The surface structure and morphology of the $\mathrm{Cu}_{\mathrm{x}} \mathrm{O}$ as well as the structure of the CNTs was studied by field-emission scanning electron microcopy (SEM) using a Zeiss Supra 60 and a Zeiss Auriga 60. Selected samples were studied in more detail by transmission electron microscopy (TEM). A Phillips CM20 FEG TEM equipped with Imaging Energy Filter by Gatan (GIF) was used for these investigations. The CNTs were prepared for TEM by pulling TEM grids over the CNT samples. The chemical composition of the CNTs embedded in vias was analyzed by energy dispersive $X$-ray spectroscopy (EDX). For these investigations Bruker X-Flash 5030 and 5010 setups were used. These detectors are attached to the SEM tools mentioned above. In contrast to the SEM images, for which cross-sections of the CNT samples were used, the EDX measurements were performed perpendicular to the substrate surface to ensure that always the same amount of CNTs was excited by the electron beam.

Raman spectroscopy was used to determine the defect density of the CNTs by the ratio of the D- and G-peaks in the Raman spectra of CNT samples [23]. Measurements were performed with a Horiba Scientific LabRAM HR using an $\mathrm{Ar}^{+}$ion laser excitation $(\lambda=514.5 \mathrm{~nm})$. For comparison, the Raman spectra were smoothed via FFT filter and normalized to the G-band.

\section{Results and Discussion}

In order to study how various pretreatments influence the subsequent $\mathrm{Cu}_{\mathrm{x}} \mathrm{O}$ ALD process, a CNT sample was prepared that was not oxidized prior to the ALD process. The $\mathrm{Cu}_{\mathrm{x}} \mathrm{O}$ ALD on these pristine CNTs causes a uniform thickening of the nanotubes as revealed by SEM inspection (Fig. 3). However, a more detailed study of these samples by TEM revealed that there are also areas were no $\mathrm{Cu}_{\mathrm{x}} \mathrm{O}$ deposition occurs, see Fig. 4. Probably, only on the parts of the CNTs that are contaminated with moisture or organic impurities being physisorbed on the CNTs during storage, $\mathrm{Cu}_{\mathrm{x}} \mathrm{O}$ deposition occurs, since it is expected that no ALD is possible on perfect CNTs surfaces [24]. Probably these contaminations are stabilized on the CNTs during the first ALD cycles analogous to the pre-treatment of the CNTs with $\mathrm{NO}_{2}$ [16]. However, during the pre-treatment these impurities might desorb from the CNTs. Therefore only defect sites of the pre-treated CNTs are decorated with ALD $\mathrm{Cu}_{\mathrm{x}} \mathrm{O}$ due to the higher reactivity of these sites since it is expected that only at these defects chemisorption of the precursor can occur [25].

The formation of copper oxide particles with a diameter of approx. $20 \mathrm{~nm}$ was observed by SEM on CNTs pretreated with oxygen or water vapor at $300^{\circ} \mathrm{C}$, see Fig. 5 and 6 . However, even if the oxidation temperature was below $300^{\circ} \mathrm{C}$, particles were formed. Since they have a diameter of approx. $4 \mathrm{~nm}$, they can only be observed by TEM, see Fig. 7. Potentially, an oxidation with oxygen or water vapor at $300^{\circ} \mathrm{C}$ attacks the outer shell of the CNTs and therefore creates additional nucleation sites for the ALD growth process. This increased number of nucleation sites then could cause the formation of larger $\mathrm{Cu}_{\mathrm{x}} \mathrm{O}$ particles during the 
ALD process. Only in the case of a pretreatment with wet oxygen at $300^{\circ} \mathrm{C}$, a rather layer-like growth behavior occurred, as shown by Fig. 7. The formation of particles can be explained by the low affinity of $\mathrm{Cu}$ to form carbides [26]. By their investigations of the growth behavior of metals on CNTs, Zhang et al. [26] have found that metals with many unoccupied states in the d-band will rather form a continuous layer, compared to metals with a nearly fully occupied $\mathrm{d}$-band. Since the $\mathrm{d}$-band of $\mathrm{Cu}$ has only two vacancies, it appears not surprising that $\mathrm{Cu}_{\mathrm{x}} \mathrm{O}$ tends to form particles on CNTs. However, since the study by Zhang et al. [26] is on pure metals, the interaction of the ALD layer with the CNTs will possibly change after the reduction of the $\mathrm{Cu}_{\mathrm{x}} \mathrm{O}$. This could cause a change of the shape of the deposited $\mathrm{Cu}_{\mathrm{x}} \mathrm{O}$.

Moreover, a weak interaction between the precursor and the CNTs might has to be considered. Potentially the precursor bonds only to the CNT surface by the interaction of the quasi-m-electron systems of the acetylacetonates with the substrate as described by Kenvin et al. [27]. Maybe after the oxidation step the $\mathrm{Cu}_{x} \mathrm{O}$ is likewise only weakly bonded to the CNTs. As a consequence, the $\mathrm{Cu}_{x} \mathrm{O}$ is able to diffuse on the CNT surface. This could enable coalescence of the $\mathrm{Cu}_{x} \mathrm{O}$ to particles at defect sites of the CNTs, where the interaction between the $\mathrm{Cu}_{\mathrm{x}} \mathrm{O}$ and the CNTs is stronger. Depending on the type and number of defect sites introduced by the pretreatments to the CNTs, the size and shape of the $\mathrm{Cu}_{\mathrm{x}} \mathrm{O}$ may vary as seen in the current investigations. For example, it is expected that a two-dimensional growth requires a high density of defect sites, so that the $\mathrm{Cu}_{x} \mathrm{O}$ disperses uniformly and does not form particles.

This is in line with the paper of Egelhoff et al. [28] who reported that on graphite twodimensional growth of copper is enabled after extensive ion bombardment. In contrast, cluster formation occurs on crystalline graphite surfaces. Therefore, a partial destruction of the outer CNT shell by the oxidation can probably explain the occurrence of areas with layer-like ALD growth after a pretreatment with wet oxygen at $300^{\circ} \mathrm{C}$. Since it is known that the combination of oxygen and water vapor ("wet oxygen") is a stronger oxidizing agent than oxygen or water vapor separate from each other, it is expected for enabling layer-like growth with oxygen or water vapor pre-treatments higher temperatures are necessary. Potentially the oxidation temperature that is required to enable two-dimensional growth of $\mathrm{Cu}_{\mathrm{x}} \mathrm{O}$ can be lowered if a more aggressive oxidation agent, such as $\mathrm{O}_{3}$ is used. Even though the results suggest that parts of the MWCNTs surface are destroyed during the oxidation with wet oxygen at $300^{\circ} \mathrm{C}$, the vertical alignment of the CNTs was retained, as depicted by Fig. 8 .

Because these results suggest that parts of the CNT surface are destroyed due to the oxidation Raman spectroscopy was applied to compare the defect density of the CNTs after the oxidation and the following ALD. In general, the damage introduced to the CNTs during the oxidation was not measurable. Even though Fig. 9 shows some variations of the defect density within a range of 0.1 , these variations are within the standard deviation of the D-to-G-Peak ratio of the pristine CNTs. These variations of the defect density are caused by changes of the CNT growth in dependence of the position on the wafer. One Raman measurement per sample was carried out after the ALD processes, since all these experiments have been done with small pieces of one CNT wafer, in order to minimize the variations in the properties of the CNTs used. Therefore, no dispersion of values can be specified for the Raman investigations on these samples. An additional challenge for the determination of differences in the defect density of MWCNTs is the following: It is expected that during the pre-treatment only the outer shell of the MWCNTs is attacked. Therefore, the Raman signal of the outer shell is superimposed with the Raman signal from the inner shells which remain most likely unchanged during the oxidation and the ALD. Hence, it is not 
possible to detect any change in the defect density of the MWCNTs. Possibly the outer shell of the MWCNTs is attacked during the oxidation, but the damage introduced to the CNTs is smaller than the originally already existing dispersion of the defect densities of the CNTs.

After the ALD, the Cu-to-C ratio on the CNT samples was determined by EDX. The analyses show that the highest copper content was obtained after pre-treatments with oxygen, independently of the oxidation temperature, as seen in Fig. 10. These Cu contents were comparable to the values obtained after copper oxide ALD on pristine CNTs only stored in air. For all other pretreatments, i.e. with water vapor or wet oxygen, lower Cu contents are obtained. This suggests that the ALD from the $\left[\left({ }^{n} \mathrm{Bu}_{3} \mathrm{P}\right)_{2} \mathrm{Cu}(\mathrm{acac})\right]$ precursor relies on active oxygen groups on the sample surface, which are obtained upon elongated storage in air at room temperature or during oxygen pretreatment. In contrast, with other oxidizing agents, surface groups already present could possibly be substituted by other surface groups which are insufficiently reactive towards the precursor. Nevertheless, this assumption has yet to be proven by in-situ analysis methods.

\section{Conclusions}

The ALD of $\mathrm{Cu}_{\mathrm{x}} \mathrm{O}$ by $\left[\left({ }^{\mathrm{n}} \mathrm{Bu}_{3} \mathrm{P}\right)_{2} \mathrm{Cu}(\mathrm{acac})\right]$ and wet oxygen was studied after in-situ thermal oxidation of MWCNTs selectively grown in vias. Variations of the oxidation temperature as well as the oxidation agents resulted in different growth modes of the $\mathrm{Cu}_{x} \mathrm{O}$. An oxidation with wet oxygen at $300^{\circ} \mathrm{C}$ yielded in a partially layer-like growth of the $\mathrm{Cu}_{\mathrm{x}} \mathrm{O}$. It is expected that this growth mode is connected to a partial destruction of the outer CNT shell due to the oxidation. However, the damage introduced to the CNTs was not high enough to be detected by Raman spectroscopy. For future investigations the measurement of the resistance change of the CNT vias in dependence of the pretreatments could be more sensitive in terms of the defect density of the CNTs. On the other hand, the formation of $\mathrm{Cu}_{\mathrm{x}} \mathrm{O}$ particles was observed for all other pre-treatments. This growth mode can be explained by the low affinity of $\mathrm{Cu}$ to form carbides. Furthermore, the EDX results suggest that the used precursor $\left[\left({ }^{\mathrm{n}} \mathrm{Bu}{ }_{3} \mathrm{P}\right)_{2} \mathrm{Cu}(\mathrm{acac})\right]$ requires reactive oxygen surface groups for initiating the ALD growth.

The observation of layer-like growth of $\mathrm{Cu}_{x} \mathrm{O}$ on CNTs pretreated with wet oxygen at $300^{\circ} \mathrm{C}$ appears promising for deposition processes of Cu seed layers on CNTs. However, to ensure an optimal filling of the interspaces, the two-dimensional growth has to be enabled on the whole CNT surface. Therefore more aggressive oxidations at temperatures up to $400^{\circ} \mathrm{C}$ as well as the more aggressive oxidation agent $\mathrm{O}_{3}$ could be required, since it is expected that these pretreatments are able to destroy a higher percentage of the CNT surface and thereby enable layer-like growth on the entire CNTs. Additionally further investigations have to deal with the impact of the reduction step of the $\mathrm{Cu}_{x} \mathrm{O}$ into $\mathrm{Cu}$ on the MWCNT quality as well as the shape and distribution of the $\mathrm{Cu}_{x} \mathrm{O}$.

\section{Acknowledgements}

We thank the German Research Foundation (DFG) for funding obtained within the International Research Training Group 1215 "Materials and Concepts for Advanced Interconnects and Nanosystems" as well as the Research Unit 1713 "Sensoric Micro- and Nanosystems".

[1] J. Hone, M. Whitney, C. Piskoti, a. Zettl, Thermal conductivity of single-walled carbon nanotubes, Physical Review B. 59 (1999) R2514-R2516. 
[2] P. Kim, L. Shi, a. Majumdar, P. McEuen, Thermal Transport Measurements of Individual Multiwalled Nanotubes, Physical Review Letters. 87 (2001) 19-22.

[3] C. Berger, Y. Yi, Z.L. Wang, W.A. de Heer, Multiwalled carbon nanotubes are ballistic conductors at room temperature, Applied Physics A. 74 (2002) 363-365.

[4] M. Zamkov, A.S. Alnaser, B. Shan, Z. Chang, P. Richard, Probing the intrinsic conductivity of multiwalled carbon nanotubes, Applied Physics Letters. 89 (2006) 093111.

[5] M.C. Strus, A.N. Chiaramonti, Y.L. Kim, Y.J. Jung, R.R. Keller, Accelerated reliability testing of highly aligned single-walled carbon nanotube networks subjected to DC electrical stressing, Nanotechnology. 22 (2011) 265713.

[6] ESIA, JEITA, KSIA, TSIA, SIA, International Technology Roadmap for Semiconductors ITRS. Available online at: http://www.itrs.net/reports.html (2011).

[7] N. Chiodarelli, Y. Li, D.J. Cott, S. Mertens, N. Peys, M. Heyns, et al., Integration and electrical characterization of carbon nanotube via interconnects, Microelectronic Engineering. 88 (2011) 837-843.

[8] L. Wang, Y. Zhang, Electronic and magnetic properties of metal atom adsorption on SWNT, Physica E. 43 (2011) 889-892.

[9] Y.L. Kim, B. Li, X. An, M.G. Hahm, L. Chen, M. Washington, et al., Highly Aligned Scalable Plantinum-Decorated Single-Wall Carbon Nanotube Arrays for Nanoscale Electrical Interconnects, ACS Nano. 3 (2009) 2818-2826.

[10] S. Mueller, T. Waechtler, A. Tuchscherer, O. Gordan, R. Mothes, H. Lang, et al., An Approach for $\mathrm{Cu}$ ALD via Reduction of Ruthenium-Containing $\mathrm{Cu}_{x} \mathrm{O}$ Films for the Metallization in Spintronic and ULSI Interconnect Systems, International Conference on Atomic Layer Deposition, Boston, MA (USA), June 26-29, 2011.

[11] T. Waechtler, S.-F. Ding, L. Hofmann, R. Mothes, Q. Xie, S. Oswald, et al., ALD-grown seed layers for electrochemical copper deposition integrated with different diffusion barrier systems, Microelectronic Engineering. 88 (2011) 684-689.

[12] C. Marichy, A. Pucci, M.-G. Willinger, N. Pinna, Coating of Carbon Nanotubes, in: N. Pinna, M. Knez (Eds.), Atomic Layer Deposition of Nanostructured Materials, 1st ed. Wiley-VCH, 2012: pp. 327-343.

[13] Y.-H. Lin, P.-S. Lee, Y.-C. Hsueh, K.-Y. Pan, C.-C. Kei, M.-H. Chan, et al., Atomic Layer Deposition of Zinc Oxide on Multiwalled Carbon Nanotubes for UV Photodetector Applications, Journal of The Electrochemical Society. 158 (2011) K24.

[14] C. Liu, C.-C. Wang, C.-C. Kei, Y.-C. Hsueh, T.-P. Perng, Atomic Layer Deposition of Platinum Nanoparticles on Carbon Nanotubes for Application in Proton-Exchange Membrane Fuel Cells, Small. 5 (2009) 1535-1538.

[15] H. Hiura, T. Ebbesen, K. Tanigaki, Opening and purification of carbon nanotubes in high yields, Advanced Materials. 7 (1995) 275-276. 
[16] D.B. Farmer, R.G. Gordon, Atomic layer deposition on suspended single-walled carbon nanotubes via gas-phase noncovalent functionalization., Nano Letters. 6 (2006) 699-703.

[17] S. Hermann, Growth of carbon nanotubes on different support / catalyst systems for advanced interconnects in integrated circuits, Chemnitz University of Technology, 2011. Available online at: http://nbn-resolving.de/urn:nbn:de:bsz:ch1-qucosa-78189

[18] I.Y.Y. Bu, K. Hou, D. Engstrom, Industrial compatible re-growth of vertically aligned multiwall carbon nanotubes by ultrafast pure oxygen purification process, Diamond and Related Materials. 20 (2011) 746-751.

[19] H.-K. Shin, M.J. Hampden-Smith, E.N. Duesler, T.T. Kodas, The chemistry of copper(I) $\beta$-diketonate compounds. Part V. Syntheses and characterization of $(\beta$ diketonate) $\mathrm{CuL}_{n}$ species where $\mathrm{L}=\mathrm{PBu}_{3}, \mathrm{PPh}_{3}$, and $\mathrm{PCy} y_{3} ; \mathrm{n}=1$ and 2 ; crystal and molecular structures of $(\mathrm{acac}) \mathrm{Cu}\left(\mathrm{PCy}_{3}\right),(\mathrm{tfac}) \mathrm{Cu}\left(\mathrm{PCy}_{3}\right)$ and $(\mathrm{hfac}) \mathrm{Cu}\left(\mathrm{PCy}_{3}\right)$, Canadian Journal of Chemistry. 70 (1992) 2954-2966.

[20] T. Waechtler, Thin films of copper oxide and copper grown by atomic layer deposition for applications in metallization systems of microelectronic devices, Chemnitz University of Technology, 2009. Available online at: http://nbn-resolving.de/urn:nbn:de:bsz:ch1-201000725

[21] S.M. George, Atomic layer deposition: an overview., Chemical Reviews. 110 (2010) 111-131.

[22] T. Waechtler, S. Oswald, N. Roth, A. Jakob, H. Lang, R. Ecke, et al., Copper Oxide Films Grown by Atomic Layer Deposition from Bis(tri-n-butylphosphane) copper (I) acetylacetonate on $\mathrm{Ta}, \mathrm{TaN}, \mathrm{Ru}$, and $\mathrm{SiO}_{2}$, Journal of The Electrochemical Society. 156 (2009) H453.

[23] M.S. Dresselhaus, G. Dresselhaus, R. Saito, a. Jorio, Raman spectroscopy of carbon nanotubes, Physics Reports. 409 (2005) 47-99.

[24] A. Javey, J. Guo, D.B. Farmer, Q. Wang, E. Yenilmez, R.G. Gordon, et al., SelfAligned Ballistic Molecular Transistors and Electrically Parallel Nanotube Arrays, Nano Letters. 4 (2004) 1319-1322.

[25] C. Marichy, J.-P. Tessonnier, M.C. Ferro, K.-H. Lee, R. Schlögl, N. Pinna, et al., Labeling and monitoring the distribution of anchoring sites on functionalized CNTs by atomic layer deposition, Journal of Materials Chemistry. 22 (2012) 7323.

[26] Y. Zhang, N. Franklin, R. Chen, H. Dai, Metal coating on suspended carbon nanotubes and its implication to metal-tube interaction, Chemical Physics Letters. 331 (2000) 35-41.

[27] J.C. Kenvint, M.G. White, M.B. Mitchell, Preparation and Characterization of Supported Mononuclear Metal Complexes as Model Catalysts, Langmuir 7 (1991) 1198-1205.

[28] W.F. Egelhoff Jr, G.G. Tibbetts, Growth of copper, nickel, and palladium films on graphite and amorphous carbon, Physical Review B. 19 (1979) 5028. 


\begin{tabular}{lc}
\hline Table I. Pretreatments \\
\hline Oxidation Agent & Process gases \\
Oxygen & $45 \mathrm{sccm} \mathrm{O}$ \\
& $210 \mathrm{sccm} \mathrm{Ar}$ \\
Water vapor & $18-20 \mathrm{mg} / \mathrm{min} \mathrm{H}_{2} \mathrm{O}$ \\
& $210 \mathrm{sccm} \mathrm{Ar}$ \\
Wet oxygen & $18-20 \mathrm{mg} / \mathrm{min} \mathrm{H}_{2} \mathrm{O}$ \\
& $45 \mathrm{sccm} \mathrm{O}$ \\
& $210 \mathrm{sccm} \mathrm{Ar}$ \\
\hline
\end{tabular}

Table II. Steps of an ALD cycle

\begin{tabular}{|c|c|c|}
\hline Description & $\begin{array}{l}\text { Pulse } \\
\text { length }\end{array}$ & Process gases \\
\hline $\begin{array}{l}\text { Precursor } \\
\text { exposure }\end{array}$ & $4 \mathrm{~s}$ & $\begin{array}{l}10-20 \mathrm{mg} / \mathrm{min} \\
\text { precursor } \\
740 \mathrm{sccm} \mathrm{Ar}\end{array}$ \\
\hline $\begin{array}{l}\text { Argon } \\
\text { purging }\end{array}$ & $5 \mathrm{~s}$ & 145 sccm Ar \\
\hline Oxidation & $8 \mathrm{~s}$ & $\begin{array}{c}18-20 \mathrm{mg} / \mathrm{min} \\
\mathrm{H}_{2} \mathrm{O} \\
45 \mathrm{sccm} \mathrm{O} \mathrm{O}_{2} \\
355 \mathrm{sccm} \mathrm{Ar}\end{array}$ \\
\hline $\begin{array}{l}\text { Argon } \\
\text { purging }\end{array}$ & $5 s$ & 145 sccm Ar \\
\hline
\end{tabular}

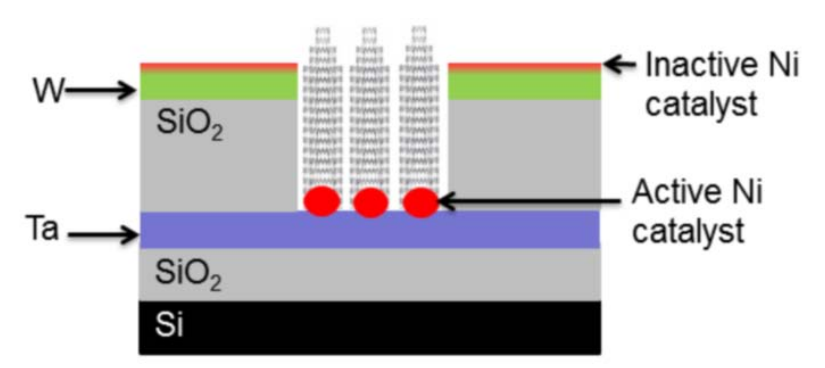

Fig. 1: Scheme of the CNT test vehicle

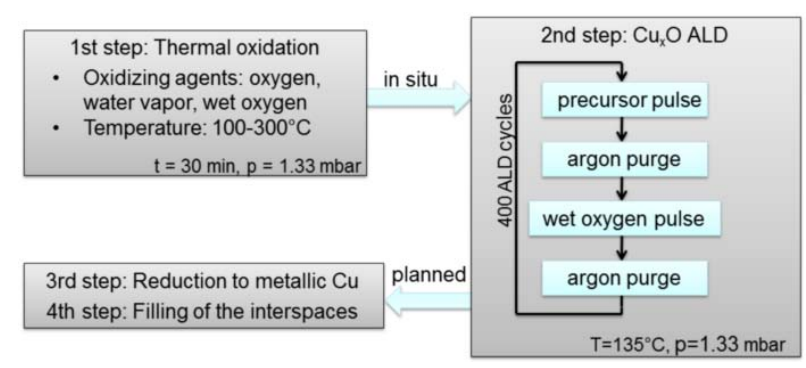

Fig.2: Process flow for the encapsulation of CNTs into $\mathrm{Cu}$

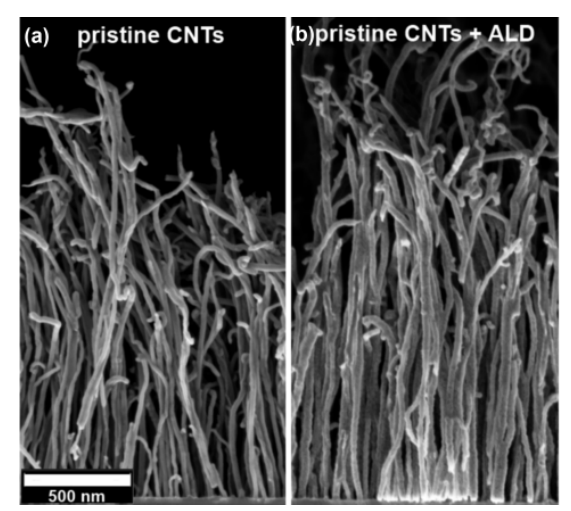


Fig. 3: SEM images of pristine MWCNTs (a) before and (b) after $\mathrm{Cu}_{x} \mathrm{O}$ ALD.

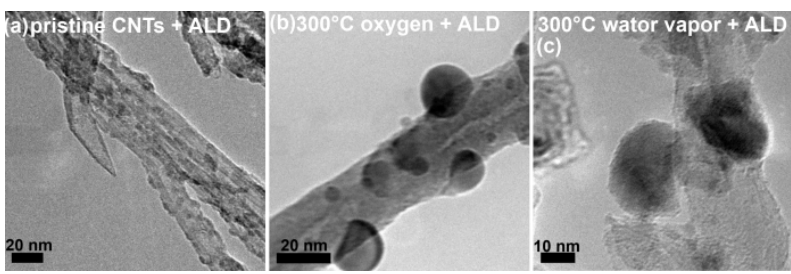

Fig. 4: TEM images of pristine MWCNTs after $\mathrm{Cu}_{x} \mathrm{O}$ ALD without a previous oxidation (a) and MWCNTs after an oxidation with oxygen (b) or water vapor (c) at $300^{\circ} \mathrm{C}$ after $\mathrm{Cu}_{\mathrm{x}} \mathrm{O}$ ALD.

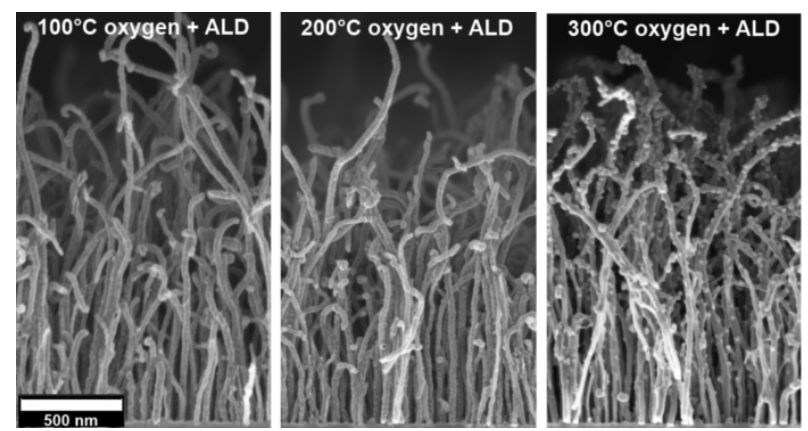

Fig. 5: SEM images of MWCNTs after an oxidation at various temperatures with oxygen and subsequent $\mathrm{Cu}_{\mathrm{x}} \mathrm{O}$ ALD.

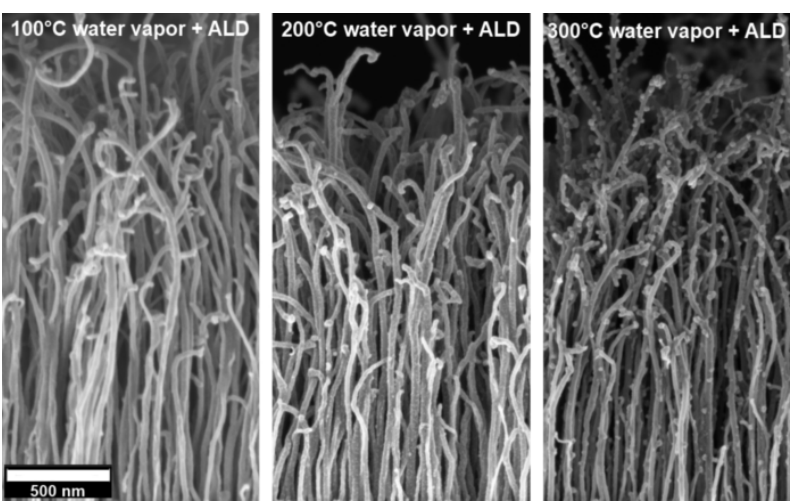

Fig. 6: SEM images of MWCNTs after an oxidation at various temperatures with water vapor and $d$ subsequent $\mathrm{Cu}_{\mathrm{x}} \mathrm{O}$ ALD.

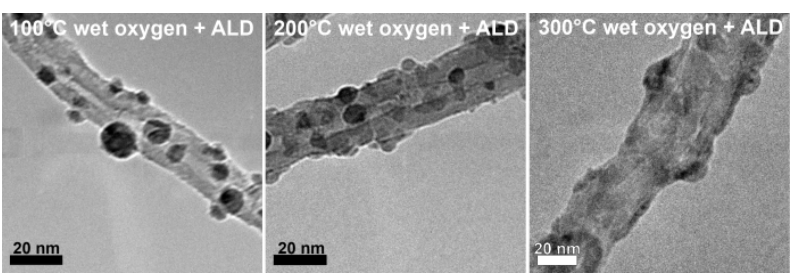

Fig. 7: TEM images of MWCNTs after an oxidation at various temperatures with wet oxygen and subsequent $\mathrm{Cu}_{\mathrm{x}} \mathrm{O}$ ALD. 


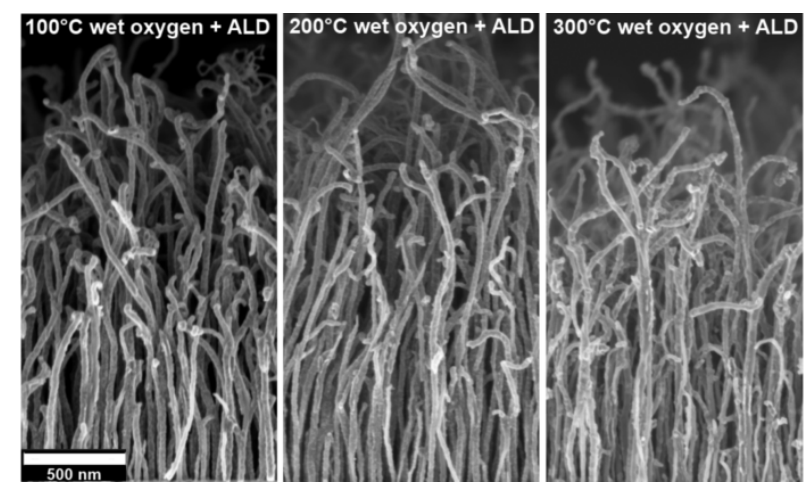

Fig. 8: SEM images of MWCNTs after an oxidation at various temperatures with wet oxygen and $d$ subsequent $\mathrm{Cu}_{\mathrm{x}} \mathrm{O}$ ALD.

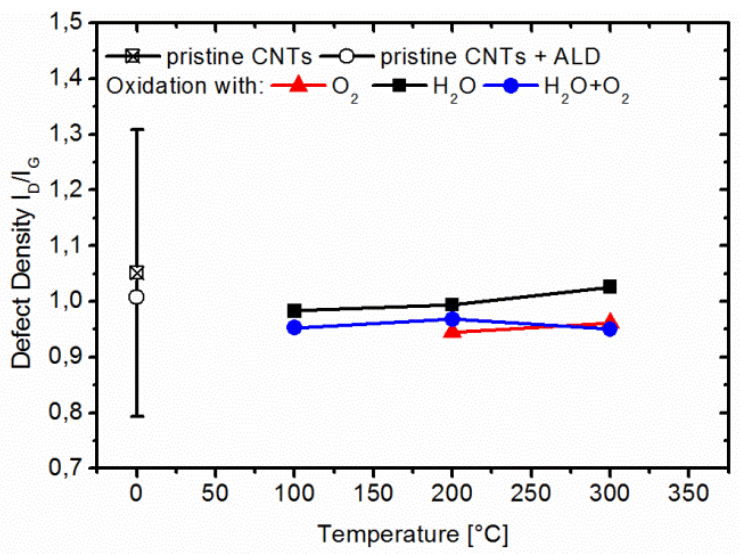

Fig. 9: Defect density of the various MWCNTs sample obtained by the $I_{D}$-to- $I_{G}$ ratio of the corresponding Raman spectra. For the pristine CNTs, the median and the standard deviation are plotted, showing that the $I_{D}$-to- $I_{G}$ ratios determined for ALD-coated CNTs after various pre-treatments are within the dispersion of values already obtained for pristine CNTs.

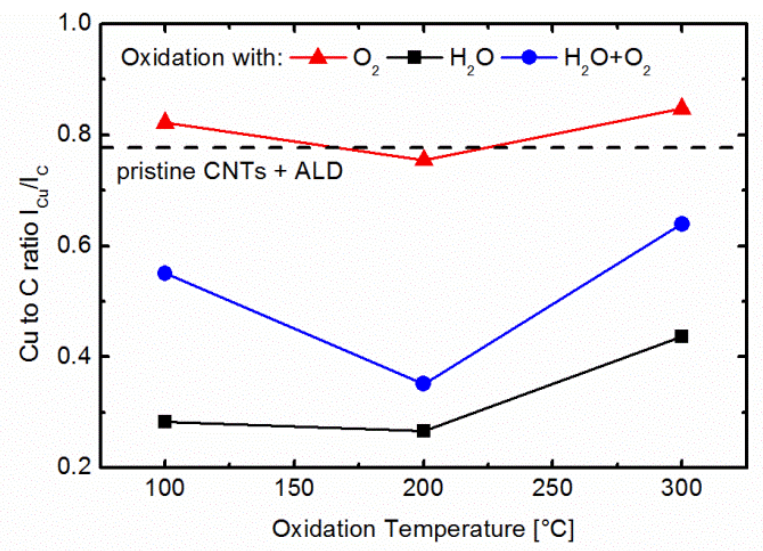

Fig. 10: Cu-to-C ratios of the various MWCNTs samples obtained by EDX. 